\title{
Arte útil para la sociedad. Consideraciones en torno a seis artistas del siglo XXI en España
}

\author{
Useful art projects, reflexions about six Spanish \\ contemporary artists
}

\author{
Victoria QUIROSA GARCÍA \\ Laura LUQUE RODRIGO \\ Universidad de Jaén
}

Resumen: ¿Debe ser el Arte útil? ¿Siente la sociedad que el Arte le pertenece? En la actualidad cada vez son más los artistas que definen su obra como un lenguaje recíproco entre su proceso creativo y los espectadores. Una relación que no siempre ha sido fácil ya que la sociedad ha adoptado una actitud meramente contemplativa y estas nuevas exigencias le obligan a participar activamente de la actividad artística. En este artículo queremos reflexionar sobre estas cuestiones analizando la trayectoria de seis artistas y colectivos actuales que reivindican a través de su obra la regeneración del espacio urbano y la supremacía del Arte como motor de cambio ante conflictos sociales. El Arte comprometido vuelve a tener un mayor peso en períodos de crisis creando un caldo de cultivo óptimo para la renovación y evolución de la disciplina artística y sus repercusiones más allá de su difusión tradicional.

Palabras clave: Arte, Sociedad, Utilidad, Reflexión, Cambio.

AвSTRACT: Art would be useful to the society? Feel the society that the art belong them? In these moments there are more artists who define their artwork as a reciprocal language between the creation and the observers. A relation that not always has been easy, because of the society not takes part actively. In this article we want to reflect about these questions analyzing the path of six artists that claim with their artwork the regeneration of the urban space and the supremacy of art as generator of change in social conflicts. The committed art contribute to renewal and development of the discipline. In critical periods is more necessary to carry out this type of actions.

Keys words: Art, Society, Useful, Reflexion, Change.

"Considero útil todo aquello que nos ayuda a hacernos mejores"1

${ }^{1}$ N. ORDINE, La utilidad de lo inútil. Manifiesto, Barcelona, 2013, p.9. 
LA INERCIA TEÓRICA: LA CREACIÓN DE UN MODELO OBJETIVO EN LA RECEPCIÓN DE LA OBRA DE ARTE

La definición del Arte está en continua evolución y es en periodos de crisis donde se refuerza su vinculación con la sociedad. Por ello, son muchos los artistas que continúan una línea marcada desde lejos por teóricos y estudiosos que reivindican el carácter terapéutico, regenerador y positivo del Arte, mientras que otros siguen trabajando en las líneas ya establecidas, con un carácter marcadamente mercantil.

¿Debe ser el Arte útil? ¿Es una condición sine qua non?. La reivindicación del placer desinteresado es una meta contemporánea. Su clasificación y definición ha venido marcada por la objetividad de la minoría, que imponía un único modelo de recepción por parte de los espectadores, que acudían al templo, al museo, al espacio sacralizado al fin y al cabo como meros catecúmenos $\mathrm{u}$ observadores. Ese modelo pasivo ha creado una serie de hábitos que hacen que el contacto con lo perfomático o con otro tipo de manifestaciones artísticas grupales o colectivas no deje de ser chocante, si bien la pluralidad del Arte nos exige una nueva actitud, unos márgenes diversos para nuestra implicación en el proceso o el resultado creativo.

La percepción de la obra de Arte venía determinada también por la función/es que cumplía dentro de la sociedad receptora. Son muchos los autores que han reflexionado sobre este tema. Si bien es verdad que a modo de resumen podemos destacar dos grandes bloques ideológicos formados por la herencia platónica y aristotélica que se extiende desde el siglo $\mathrm{V}$ a.C. hasta el siglo XVIII, reformulada una y otra vez durante el Medievo y la Edad Moderna ${ }^{2}$ y la visión contemporánea radicalmente opuesta que se empieza a fraguar con autonomía a par-

\footnotetext{
${ }^{2}$ W. TATARKIEWICZ, Historia de la Estética I-II-III:
} La estética antigua, Madrid, 2014. tir del $\mathrm{XVIII}^{3}$ y que dota al individuo de una mayor capacidad para decidir y valorar la función o funciones que debe tener la obra de Arte. Así lo ratifica Adam Smith cuando afirmó en 1759: "La utilidad es una de las principales fuentes de la belleza [...] la capacidad de cualquier sistema o artilugio de alcanzar el fin para el que fue creado otorga cierta conveniencia y belleza al resultado final, y hace agradable el hecho de pensar en él o contemplarlo"

La autonomía del Arte, como disciplina científica a partir del siglo XVIII, validó y actualizó la presencia de valores ajenos a lo plástico que condicionaron la experiencia estética del individuo, dejando atrás la objetividad de lo funcional. El origen de la autonomía lo situamos en el pensamiento ilustrado, en el que autores como Kant y Baumgarten desarrollaron cuestiones esenciales para la Estética como disciplina independiente. Fueron las nuevas ramas del Arte las que justificaron y asumieron el carácter funcional, pensemos en el valor emergente del diseño gráfico e industrial a partir del siglo XIX ${ }^{5}$. Lo utilitario se caracterizará también por un modelo de producción seriada ya sea artesanal o industrial.

Pero el germen de cambio quedará asentado por el discurso ideológico de las vanguardias y las aportaciones teóricas de filósofos como Ortega y Gasset o Theodor Adorno, entre otros, que son muy representativas de los cambios operados en este periodo. La ruptura con lo preestablecido será el punto de partida para estos autores y así lo expresaba T. Adorno en su obra Mínima Moralia: "Es preciso fijar perspectivas en las que el mundo aparezca trastrocado, enajenado, mostrando sus grietas y desgarros, menesteroso y deforme en el grado en que apa-

\footnotetext{
${ }^{3}$ V. BOZAL (coord.), Historia de las Ideas Estéticas y de las teorías artísticas contemporáneas I-II, Madrid, 1996.

${ }^{4}$ AA.VV., La utilidad en el diseño, Madrid, 2008, s.p.

${ }^{5}$ Para ampliar información recomendamos P. B. MEGGS, Historia del Diseño Gráfico, Barcelona, 2009. B. E. BURDEK, Diseño. Historia, Teoría y Práctica del Diseño Industrial, Barcelona, 1994.
} 
rece bajo la luz mesiánica. Situarse en tales perspectivas sin arbitrariedad ni violencia, desde el contacto con los objetos, sólo le es dado al pensamiento" ${ }^{\prime \prime}$.

La liberación de los cánones y normas ofrece al Arte infinitas posibilidades, entre las que se encuentra su capacidad para ser o no útil, pues dicha justificación ya no es necesaria. Para Adorno: “(...) El Arte auténtico, viene a decir, es libre y debe seguir siéndolo porque su libertad es garantía de libertad para el hombre en una sociedad opresiva y cosificadora"7.

La cara y la cruz es la impopularidad del Arte nuevo, como vemos en el texto de Ortega y Gasset, La deshumanización del Arte: "En cambio, el Arte nuevo tiene a la masa en contra suya, y la tendrá siempre. Es impopular por esencia; más aún es antipopular. Una obra cualquiera por él engendrada produce en el público automáticamente un curioso efecto sociológico. Lo divide en dos porciones; una mínima, formada por un reducido número de personas que le son favorables; otra, mayoritaria, innumerable, que le es hostil. (...) Actúa, pues, la obra de Arte como un poder social que crea dos grupos antagónicos, que separa y selecciona en el montón informe de la muchedumbre dos castas diferentes de hombres" ${ }^{\prime \prime}$. La deshumanización llega a través de la desvinculación del artista con la realidad vivida, con su entorno. Obviamente el texto se dirige al Arte de vanguardia, que tiene en ese distanciamiento su razón de ser; pensemos en el cubismo o en el dadaísmo y su exploración teórico-plástica9 ${ }^{9}$.

${ }^{6}$ T. W. ADORNO, Mínima Moralia. Reflexiones desde la vida dañada, Madrid, 2003, p.153.

${ }^{7}$ F. SOSA, "Autonomía y sociedad en la estética de Theodor Adorno", A Parte Rei: revista de filosofía, 17, 2001, pp.1-15.

${ }^{8}$ H. MONTES BRUNET (coord.), Unamuno, Azorín y Ortega. Ensayos, Santiago de Chile, 1978, p. 18.

${ }^{9}$ C. NIETO YUSTA, “José Ortega y Gasset y La deshumanización del arte", Espacio, tiempo y forma, 20-21, 2007-2008, pp. 285-299.
A pesar de la fuerza y vehemencia de estos aparatos teóricos, muchos artistas comienzan a reflexionar sobre el alcance de su obra en relación a los receptores, la sociedad de su tiempo y el carácter educativo fundamental que desempeña el Arte en el desarrollo del individuo. En esa línea destacamos las reflexiones de la artista Ruth Asawa al respecto: "El Arte es para todo el mundo. No debería ser algo que para ver y disfrutar se deba acudir a los museos. Cuando trabajo en grandes proyectos, me gusta incluir a las personas que aún no han desarrollado su lado creativo. Mi anhelo es ayudar a que su creatividad salga fuera. Me gusta el diseño de proyectos en que la gente se sienta segura y no tenga miedo a involucrarse. (...) Un niño debe aprender sobre color, sobre diseño y sobre la observación de los objetos de la naturaleza. Al hacer eso, tomará una mayor conciencia sobre las cosas que le rodean. El Arte hace que la gente sea mejor, más cualificada en el pensamiento e incluso en la mejora de cualquier negocio. Hace que una persona sea más completa"10.

SOBRE LA UTILIDAD DEL ARTE. REFLEXIONES EN TORNO AL ARTE SOCIAL DEL SIGLO XXI.

La idea de la utilidad del Arte vuelve a estar presente en un tiempo de crisis donde la cultura y la educación artística se ven menoscabadas, por eso son numerosas las noticias en los mass media que recogen proyectos, obras, y experiencias relacionadas con el carácter regenerador del Arte en nuestros ámbitos más cercanos.

En la actualidad, el debate sobre si el Arte -en la más amplia acepción de la palabra- es útil o no es complejo, pues la mer-

\footnotetext{
${ }^{10}$ La inmensa mayoría de la bibliografía de la autora está publicada en inglés, por eso hemos seleccionado este recurso web en español, Blog Circarq, RUTH ASAWA (Japón 1926- San Francisco 2013), consultado el 18 de febrero de 2015. URL: https://circarq.wordpress. com/2014/05/16/ruth-asawa-japon-1926-san-francisco-2013/. No obstante recomendamos: E. URBANELLI, The sculpture of Ruth Asawa: Contours in the air. San Francisco, 2007.
} 
cantilización de todos los campos del saber y de la práctica han promovido que se considere inútil todo aquello que no produce un beneficio, que entendemos en la mayoría de los casos como económico. Ante esto sólo se puede responder que los beneficios que aportan los saberes humanísticos y la experiencia artística van mucho más allá de lo económico, aunque el mercado también pueda formar parte del juego. Sobre el tema han reflexionado autores tan dispares como Ionesco, Rilke, Rostand u Okakura, quienes han comprendido "la utilidad de lo inútil" y la importancia de la experiencia. De todo esto trata en su libro magistralmente, Nuccio Ordine, quien afirma que: "Tenemos necesidad de lo inútil como tenemos necesidad, para vivir, de las funciones vitales esenciales (...), la necesidad de imaginar, de crear es tan fundamental como lo es respirar"11. ¿Debemos asumir la inutilidad del Arte? Walter Benjamin pensaba que: "Entre los cometidos del Arte, siempre ha destacado el de suscitar una exigencia que el presente aún no podía satisfacer"12. Hoy día el escultor Jaume Plensa, Premio Nacional de Artes Plásticas 2013'3, afirma: "Creo que una obra de Arte debe contener un enigma, algo imposible de resolver. El Arte debe ser de una gran inutilidad en la vida material; es cuando más fuerza tiene, más se vuelve un objeto de deseo y más imprescindible es" ${ }^{14}$.

La idea del Arte por el Arte surge casi al mismo tiempo que el Arte social. Esto tiene calado en las nuevas técnicas artísticas como el cine o la fotografía que se mueven a medio camino entre lo documental y lo estético confirmando su función social.

\footnotetext{
${ }^{11}$ N. ORDINE, Op.cit., p.17.

${ }^{12}$ W. BENJAMIN, La obra de arte en la época de su reproducción mecánica, Madrid, 1939, p.18.
}

${ }^{13}$ AA. VV., Jaume Plensa, Milán, 2013.

${ }^{14}$ J. M. CUÉLLAR, “Jaume Plensa: El arte debe ser tan inútil que no sirva para nada, esta es su gran fuerza", RTVE, 17 de febrero de 2015, consultado el 17 de febrero de 2015. URL: http://www.rtve.es/noticias/20150217/ jaume-plensa-arte-debe-ser-tan-inutil-sirva-para-nadaesta-gran-fuerza/1099604.shtml
Parece, sin embargo, que son necesarias las grandes crisis económicas, sociales o bélicas en el peor de los casos para despertar esa inquietud, ese espíritu de lucha en los artistas del momento. Por ello, las últimas décadas del siglo XX fueron mucho menos fructíferas a este respecto. El artista aparece como una persona que debe asegurar su estatus, por lo que se le exigen resultados y una permanente actividad que lo visibilice. Algunos artistas durante la década de 1960 trataron de vivir al margen, por ejemplo Hans Haacke, que relacionó el Arte y la política, Clifford Still o Bornet Newman, entre otros, representaban un modelo de artista que partía de la reivindicación pero que a lo largo de su trayectoria terminaban por incluirse en el mercado artístico tradicional. Las bonanzas de la década de 1980 agudizaron el declive del Arte social, pero los conflictos que ha traído el siglo XXI han logrado revivir lo que parecía ya muerto. Aunque el atentado contra las Torres Gemelas de Nueva York en 2001 parece que marcó la entrada en el nuevo siglo, mostrando un nuevo tipo de guerra a gran escala, la crisis económica, que comenzó en 2008 afectando a casi la totalidad de los llamados países desarrollados, ha supuesto una nueva oleada de artistas que viven, en muchos casos, al margen del mercado y realizan sus obras de una forma en ocasiones ilegal, con el único objetivo de remover conciencias o cambiar realidades. Ejemplos tempranos son el influyente Santiago Sierra o el colectivo Wochen Klausur ("semanas de encierro") que trabaja desde 1993 en propuestas artísticas orientadas a reducir las diferencias socio-políticas, bajo la premisa de que una de las funciones del Arte ha sido siempre la transformación de las condiciones de vida. El método de trabajo propone la unión del equipo durante varias semanas de alto rendimiento, si bien lo hacen siempre previa invitación de una institución y en salas de Arte.

Un caso más reciente es el del conocido artista francés JR., que cuando recibió el premio TED en 2011 ya se planteaba si el Arte podía cambiar el mundo, llegando a 
la conclusión de que "el hecho de no poder cambiar el mundo, hace que el Arte sea un lugar neutral para cambios y discusiones, es en este punto donde puede cambiar el mundo"15.

Una acción artística que ha influenciado a otras es la de Ygor Marotta y su Mais amor por favor. Otros artistas como Nuria Güell, Pilar Albarracín, The Eyes Men o Favela Painting, entre otros muchos, trabajan en la misma línea. En los últimos años además se han sucedido conferencias y artículos de prensa en España, Portugal e Italia que pretenden ahondar en la posibilidad de que el Arte sea un motor para cambiar realidades. Un Arte que explora a través de su temática o del efecto que produce en el espectador nuevos retos en el terreno de lo emocional, para J. L. Moraza: "Para el Arte, los temas que trata son menos importantes que el Arte; para los temas que trata el Arte, el Arte es menos importante que los temas que trata"16.

En la actualidad también son decisivos proyectos globales como ha sido la exposición temporal en el MNCARS "Un saber realmente útil" fomentando un lenguaje recíproco entre los proyectos artísticos y la sociedad que los acoge, testigos de un compromiso plástico y verbal que suele adoptar posturas nunca neutrales: "La forma en que las sociedades definen y distribuyen el conocimiento indica el modo en que se estructuran, el orden social dominante y los grados de inclusión y exclusión. La exposición Un saber realmente útil investiga diversas situaciones educativas heterodoxas, espontáneas, antijerárquicas, no académicas, procedimentales y centradas fundamentalmente en el potencial transformador del Arte. En la muestra se suceden diversos temas recurrentes que giran en torno a la relación entre

\footnotetext{
${ }^{15}$ JR, Discurso del Artista JR. en los Ted Prize (2011), consultado el 9 de febrero de 2015. URL: http://www. ted.com/talks/jr_s_ted_prize_wish_use_art_to_turn_ the_world_inside_out?language $=\mathrm{es}$

${ }^{16}$ J. L. MORAZA y J. FERNANDES, República, Madrid, 2015.
}

el artista y el cambio social, la dialéctica implícita en las imágenes y en el ámbito visual susceptible de generar acción política, y la tensión entre la necesidad de implicación activa y la insistencia en el derecho del Arte a ser "inútil"17. En España han surgido artistas $\mathrm{y}$ colectivos que trabajan en este sentido, a continuación se expondrán los trabajos y las reflexiones de seis de ellos.

\section{ARTE EN TIEMPOS DE CRISIS. SEIS PROPUESTAS CREATIVAS ${ }^{18}$}

"Todos podemos trasformar el mundo desde el lugar que ocupamos. No hacer nada ya es en sí mismo hacer algo: es un silencio cómplice que apoya las cosas que pasan $^{\prime 19}$.

\section{ISIDRo LóPEZ-ApARICIO}

Artista multidisciplinar y profesor en la Universidad de Granada, su compromiso personal impregna sus proyectos artísticos que han girado en torno la denuncia social. Su desarrollo personal y profesional se ha movido dentro del mundo de la cooperación, tanto local como internacional, de forma voluntaria y profesional. Su inquietud hacia este tipo de Arte surge en su juventud, aun en la etapa formativa. La primera obra que realizó en este sentido fue un collage colectivo en un centro de reinserción de drogadictos. Su trabajo parte de las personas y lo entiende como un proceso comunicativo al margen de los canales de comunicación habituales, que puede por tanto transformarse en un elemento social. Le interesan todos los

17 AA.VV., Un saber realmente útil. Catálogo de la exposición del Museo Nacional Centro de Arte Reina Sofía, Madrid, 2014.

${ }^{18}$ La selección de los artistas de los que hablaremos a continuación obedece a la singularidad de los proyectos desarrollados y su repercusión mediática en las primeras décadas del siglo XXI, que es el periodo sobre el que estamos reflexionando en este texto. Agradecemos a todos ellos su implicación para la elaboración de este artículo, sin la cual no hubiera sido posible.

${ }^{19}$ Y. DOMÍNGUEZ (Correo electrónico, 12 de septiembre de 2014) 
temas que afectan a las personas, sus conflictos y sus relaciones, tratando siempre de captar los distintos puntos de vista. Él cree, por tanto, que el Arte puede ser útil para la sociedad, al menos en cuanto a provocar una reflexión en el observador: "El Arte en su propia esencia tiene el potencial de propiciar la observación, de hacer pensar, de generar vínculos, aptitudes, sensaciones... las cuales en distinta escala cambian al observador" ${ }^{20}$.

López-Aparicio ${ }^{21}$ crea su obra con una finalidad político-social, especialmente con la idea de crear una consciencia individual y colectiva con respecto a los temas que trata, como el conflicto saharaui, muy presente en su trabajo. No obstante, otorga utilidad también al llamado "Arte por el Arte", por lo que más que catalogar su trabajo como "Arte útil", habría de hacerse como "Arte de compromiso". En este sentido crea sobre todo lo que denomina "art tool box", útiles $\mathrm{y}$ herramientas que sirven para solucionar problemáticas específicas y que pueden ser disfrutadas por otras personas. Su recorrido personal y profesional le han llevado a desarrollar esta y otras tipologías propias del Arte, distintas de aquellos que se han acercado al mundo del conflicto por "moda". Cree que la creación artística con utilidad social puede trabajarse tanto desde lo local como desde lo internacional, pero en su caso ésta última faceta le ha ofrecido mayores oportunidades y logros. No obstante, ha realizado algunos art tool box con una expectativa local, como Curring, un video en el que reivindica un empleo digno para los titulados superiores o Wifilift procomún - Expuesto dentro del proyecto Be Virus My Friend, en la Casa Encendida, Madrid-, un proyecto que parte de un estudio legal que permite difundir el uso de internet a bajo coste empleando el teléfono del ascensor para contratar wi-fi para toda la comunidad. Su creencia en el asociacionismo le ha llevado a promover la crea-

${ }^{20}$ I. LÓPEZ APARICIO (Correo electrónico, 9 de agosto de 2014).

${ }^{21}$ Consultado el 9 de febrero de 2015. www.isidrolopezaparicio.com ción de varios grupos artísticos o colectivos y de la UAVA.

\section{Yolanda Domínguez}

Esta artista plástica, vinculada al mundo educacional, realiza acciones específicas de ámbito social y en ocasiones ligadas a asociaciones concretas como Médicos del Mundo o Greenpeace. Su obra se mueve sobre todo en el campo de la acción artística, puesto que considera que la participación del espectador tiene un poder transformador mayor que la simple contemplación, por ello involucra personas para crear experiencias en vez de objetos. Con una gran proyección mediática de los videos y fotografías que recogen dichas acciones performáticas, Yolanda Domínguez entiende el Arte de una forma similar a Isidro López-Aparicio, en cuanto a que se atribuye un papel como comunicadora, fomentando la reflexión sobre algunas temáticas. "El Arte puede ayudar a visibilizar conflictos, unir personas y servir de vehículo expresivo. Todo esto a su vez puede generar reflexión y movimiento. Creo en el Arte como un campo de acción y en la figura del artista como catalizador de lo que está pasando en su cultura. El Arte puede servir de estímulo y convertirse en motor social" 22 .

Su obra está ligada al momento actual, al contexto que la rodea. Con ella pretende visibilizar asuntos de los que generalmente no se habla, en numerosas ocasiones ligado a temas de género, de imagen y publicidad. De hecho, adopta una posición crítica con respecto a los medios de comunicación que insensibilizan a la sociedad: "Creo que nuestra sociedad nos prepara para el placer constante y el adormecimiento general. Creo que el Arte debe posicionarse ante todas esas imágenes de los mass media que pretenden anestesiarnos, con propuestas que no nos hagan soñar sino despertarnos del sueño" ${ }^{23}$.

${ }^{22}$ Y. DOMÍNGUEZ (Correo electrónico, 12 de septiembre de 2014).

${ }^{23}$ Ibídem. 
Cree que el trabajo local puede posicionarse como universal. Apoya el trabajo colaborativo, al que trata siempre de volver. El primer proyecto en el que jugó con el "binomio creador/espectador" - en sus propias palabras-, fue Princesas 2.8. (2008), un proyecto que pretendía actualizar el rol femenino de las princesas de los cuentos, un sujeto pasivo que espera la llegada del príncipe azul para alcanzar la felicidad. La acción consistió en situar a seis actrices en plena calle, representando a seis princesas de cuentos, para vender en el top manta los objetos de la historia, como forma de empezar una nueva vida, sin necesidad de un héroe que las rescate. En 2010 realiza una acción que ataca la idea de nuestra sociedad que impone a la mujer el papel de compradora compulsiva, Pido para un Chanel, para ello cuenta con una actriz que en plena calle pide dinero para comprarse una prenda de la marca. En Poses (2011) vuelve a tratar el tema de los roles femeninos, realizando una crítica directa a la artificialidad del mundo de la moda, difundido mediante las revistas, que emiten una imagen distorsionada de la mujer, que posa en actitudes humillantes para ella ${ }^{24}$.

En este sentido se mueven otras intervenciones como Vuelvo en 5 minutos (2012), Fashion victims (2013), La reina de las fiestas (2013) o No soy sólo un cuerpo (2014), entre otras muchas. Algunas de sus acciones creativas han rebasado su propia autoría, como la reciente Registro (2014), acción colectiva en la que mujeres de distintas ciudades de España acudieron a los Registros mercantiles para registrar la "propiedad" de su cuerpo, como protesta por el Anteproyecto de Ley del Aborto presentado por el ministro de Justicia Alberto Ruiz-Gallardón ese mismo año. En la actualidad trabaja en la aplicación del Arte en otros campos, con la idea de posicionarlo como una "plataforma de reflexión asociado a unos valores que pue-

\footnotetext{
${ }^{24}$ Consultado el 10 de febrero de 2015. http://www. yolandadominguez.com/es/
}

dan transmitirse a otras disciplinas"25, especialmente el educacional a través del trabajo experiencial, y el mundo de la publicidad; recientemente para este campo ha escrito un capítulo para el libro "La empresa como agente de cambio" del publicista José Carlos León Delgado.

\section{Claudia Frau}

Centrada en la fotografía y el video, sus obras se enmarcan dentro de la corriente de poesía visual, en su caso con una gran claridad formal y de carácter conceptual. Su labor artística se mueve en el campo de la reivindicación social dentro de un contexto actual, aunque también crea obras con un carácter más personal. Algunas de ellas tienen una gran carga política, como Medios de desinformación (2014), una crítica a los medios de comunicación que nos informan de la realidad; en otras hace una reflexión social, como en No te quiere, una fotografía con un lema en el que hace una clara referencia a la violencia machista; la crítica a los roles femeninos aparece en obras como Ya llega el veranito, una obra en la que sitúa un desnudo femenino con marcas en la piel que aluden a las imágenes que vemos en las carnicerías, donde se dibujan las partes de los animales. Otra crítica importante en esta línea la vemos en el video Ponte guapa, una reivindicación hacia los grupos de Vejer de la Frontera que pretendían retomar el atuendo "tradicional" de las mujeres vejerianas, que recuerda demasiado a un burka ${ }^{26}$. Pero han sido los años de la crisis económica los que la han impulsado a crear toda una línea reivindicativa de los modelos políticos y económicos actuales, hasta el punto de que una de sus fotografías se ha convertido en imagen de la lucha contra los desahucios. Se trata de un collage fotográfico que juega con escenas de la película Psicosis de Alfred Hitchkock.

${ }^{25}$ Y. DOMÍNGUEZ (Correo electrónico, 12 de septiembre de 2014).

${ }^{26}$ Consultado el 10 de febrero de 2015. http://claudiaquadefrau.blogspot.com.es/ 
Toda esta creación artística social y reivindicativa emerge de su propia concepción del Arte como catalizador de unas realidades que al mostrarlas provocan una reacción crítica y reflexiva. Esto lo propone no sólo desde el punto de vista social y político, sino también en clave de humor e ironía o simplemente desde lo bello y lo metafísico. El impulso creador parte de una necesidad de "vomitar algo que me corroe en las entrañas por tantas injusticias, me siento moralmente obligada a ello. Pensar lo fácil que sería hacerlo todo bien. Pero vivimos en una sociedad en la que nos enseñan a ser así y que para que a uno le vaya bien parece que tiene que pisotear al otro y no es así, no tendría que ser así" ${ }^{\prime 2}$.Confiesa haberlo sentido desde la infancia, en sus primeros trabajos, aunque más soñadores, abordaba temas como la sequía, el proceso de urbanización descontrolado, etc., pero "ahora mismo vivimos en un estado de emergencia social me es imposible mirar hacia otro lado y fingir que no pasa nada" 28 , y esto ha hecho que su obra se vuelque aún más si cabe en estas temáticas sociales, no sólo en defensa de los derechos ciudadanos sino también animales, como reflejan sus últimos proyectos que denuncian las prácticas de las industrias cárnicas.

\section{BASURAMA}

Colectivo formado en 2001 en el seno de la Escuela de Arquitectura de Madrid, se dedican al estudio y la actuación en los procesos productivos, en la generación de desechos que implican y en sus posibilidades creativas. El grupo busca residuos, estudia sus formatos y desarrolla actividades en las que ponen en contacto personas del entramado social que ocupan distintas posiciones. Sus proyectos tienen un carácter internacional y una gran repercusión social. La reflexión en torno a la enorme acumulación de basura que produce la sociedad de consumo les lleva a plantearse el riesgo que supo-

\footnotetext{
${ }^{27}$ C. FRAU (Correo electrónico, 12 de diciembre de 2014).

${ }^{28}$ Ibídem.
}

nen estos residuos para la propia sociedad, especialmente aquellos deshechos no orgánicos, que resultan casi indestructibles. Ante esto programan una investigación en torno a los desechos como recurso artístico, que les plantea soluciones no sólo a este problema sino a otros que se generan en las grandes y deshumanizadas metrópolis ${ }^{29}$.

Proponen crear un beneficio social mediante el uso de los desechos que la propia sociedad genera, desde una concepción colectiva. En este marco se organizan una serie de proyectos de creación de auto parques implantado en ciudades de diversos continentes como Lima (Perú), Niamey (Níger), Maputo (Mozambique), Addis Abeba (Etiopía) o Malabo (Guinea Ecuatorial). En estos auto parques, implican a los habitantes de barrios degradados de las ciudades para construir entre todos un espacio para el ocio infantil en un lugar en desuso y partiendo de materiales de desecho y de recursos locales. Los proyectos no sólo generan un espacio y unos objetos utilizables por la ciudadanía, sino que se plantean además como educacionales, es decir, el proceso de formación de los voluntarios proporciona a los participantes una experiencia artística, creativa, de convivencia social y unión colectiva, que va más allá del disfrute posterior del espacio regenerado. Estas experiencias se han realizado también en España, por ejemplo en la pequeña localidad de El Carpio (Córdoba).

Además han trabajo en otros proyectos como Autobarrios. Estrategias para practicar más barrio, que pretenden la creación de un imaginario urbano común como instrumento para crear estrategias que impulsen la creatividad de la comunidad. También imparten talleres relacionados con la investigación de procesos relacionados con el consumo y la basura como Cara-B, que a través del Instituto Cervantes se ha llevado a diversas ciudades del mundo. Igualmente realizan intervenciones artísticas, poemas visuales

${ }^{29}$ BASURAMA (Correo electrónico, 3 de noviembre de 2014). 
urbanos que parten de la reutilización de material de desecho como bolsas de plástico.

\section{Boa Mistura}

Al igual que Basurama, este colectivo que hunde sus raíces en el graffiti se creó en 2001 en Madrid, con el objetivo de desarrollar proyectos en el espacio público que permitan transformar las calles y crear vínculos entre las personas que las transitan a diario, desde el compromiso con la ciudad y el contexto en que vivimos. El nombre bajo el que trabajan, Boa Mistura, significa en portugués "buena mezcla" y hace referencia al carácter multidisciplinar de sus integrantes, cinco creadores con formación diversa como arquitectura, Bellas Artes, ingeniería de caminos, ilustración y publicidad. Cuentan además con colaboradores ocasionales de distintos sectores. Todos ellos abandonaron sus ámbitos de estudios por comenzar con una actividad artística, en sus inicios rozando los márgenes de la ilegalidad, por una convicción profunda de cambio social a través de la intervención en las ciudades. Sus creaciones pretenden tener un efecto en la sociedad similar al que pueda tener un médico con respecto a la salud o un mecánico que repara aparatos electrónicos, es decir, el de curar o reparar problemas sociales desde lo experiencial, lo colectivo. El Arte urbano es la forma para conectar con las personas, la ciudad es un soporte inmenso, libre del mercado del Arte, con una relación directa con los ciudadanos, ávidos o no de cultura. $\mathrm{Su}$ fin es mejorar el soporte que intervienen, a veces de forma muy sencilla, como pintar/ limpiar con blanco muros castigados por el deterioro o el vandalismo, creando retratos de artistas. Creen firmemente que el Arte tiene capacidad de "estremecer, de inspirar, de emocionar...por eso es tan importante" ${ }^{\prime 30} \mathrm{y}$ tiene capacidad para cambiar el mundo.

${ }^{30}$ BOA MISTURA, Arte urbano para transformar. Tedx Madrid. 9 de octubre de 2012, consultado el 10 de febrero de 2015. URL:https://www.youtube.com/ watch? $\mathrm{v}=\mathrm{gKRNLXghU94 \# t=431}$
Pero si por algo son conocidos es por sus acciones de "acupuntura colectiva en el espacio público" ${ }^{31}$ es decir, las palabras con mensajes positivos y colores alegres que iluminan los muros de las ciudades. Mensajes como "alegría", "inspiración", "la imaginación nos hace infinitos", o el proyecto Te comería a versos (Madrid, 2014), realizado con poetas para llenar de frases inspiradoras los pasos de peatones de calles hipertransitadas a demasiada velocidad. En Lima dibujaron la palabra Futuro en una especie de árbol de la vida; en Malabo (Guinea Ecuatorial), Respira el momento; en Ciudad del Cabo, Diamond inside; o en Berlín recrearon un abrazo intenso entre las dos Alemanias.

Cuando la burocracia reprime o dificulta estas manifestaciones, como es el caso de Madrid, emplean otras tonalidades como el gris para mensajes como "Madrid te quiero en colores", acciones ilegales efímeras, ya que no duran en las paredes más de una semana. En otras ocasiones emplean no sólo el lenguaje textual sino también visual en proyectos con vocación de perdurabilidad y en algunos casos recurren a la técnica de la anamorfosis. Uno de los elementos más interesantes de sus intervenciones es la vinculación conceptual con el sitio en el que trabajan, pero sobre todo, la implicación de los ciudadanos en las creaciones, de forma que no sólo modifican su entorno sino la forma de relacionarse con él. Esta experiencia la llevaron a cabo por primera vez en el barrio de Woodstocka en las afueras de Ciudad del Cabo (Sudáfrica, 2011), donde pintaron inspirados en testimonios de los vecinos y la fuerte presencia ideológica de Mandela. Por ello crearon frases como "Discover the diamond inside you" o "Pelea por tus sueños".

Estos Crossroads ${ }^{32}$, los han repetido en lugares como las favelas de Vila Brasilandia (periferia de Sao Paolo, Brasil), en el Chorri-

\footnotetext{
${ }^{31}$ Consultado el 10 de febrero de 2015. URL: http:// www.boamistura.com/index.html

${ }^{32}$ BOAMISTURA (2014). Crossroads. A Project by Boamistura., consultado el 10 de febrero de 2015.URL:https:// dl.dropboxusercontent.com/u/8848169/01\%20DOSSIE-
} 
llo (Panamá), o el Barrio de San Cristóbal de Madrid, proyecto realizado en colaboración con Basurama. Por tanto prefieren trabajar desde lo local para implicar a las comunidades, aunque la repercusión que han tenido últimamente haya sido internacional. Su proceso de trabajo parte de un período de integración en la comunidad, recorren las calles, escuchan a los vecinos, comprenden sus problemas y sus necesidad diarias; a partir de este análisis emergen las creaciones. Es un proceso de trabajo que implica un periodo de convivencia de unas tres semanas. Boa Mistura con sus obras lo que consiguen es inspirar a las personas, por ello trabajan "con el color y su capacidad evocadora y con la palabra, que es la herramienta básica de comunicación (...). Creemos que si te enfrentas diariamente a palabras como crisis, corrupción o desempleo, tu ánimo se ve muy afectado, sin embargo confiamos en el efecto contrario si lo que lees es alegría, belleza, amor o dulzura" ${ }^{\prime 33}$. Sus pequeñas acciones consiguen pequeños logros en personas anónimas que con gestos que parecen diminutos contribuyen a cambiar realidades, como "conseguir que un vecino recoja los excrementos de un perro en una callejuela de una favela que antes de pintarla estaba de basura (...). O que un niño de siete años junte sus ahorros para comprarse unas brochas..." ${ }^{\prime 3}$.

\section{TRUTHBEHIND 404}

En este caso se trata de un estudio fundado en Madrid por César Pérez Herranz en 2011, con la idea de introducir un mayor contenido artístico en las reivindicaciones ciudadanas. El número de integrantes varía según el proyecto, generalmente trabajan entre tres y cinco personas con carácter multidisciplinar, arquitectos, filósofos, programadores, artistas 3D y otros. TruthBehind 404

RES\%20Y\%20PORTFOLIOS/2014_01_26\%20CROSSROADS_BoaMistura.pdf

${ }^{33}$ BOA MISTURA (Correo electrónico, 30 de junio de 2014 y 16 de octubre de 2014).

${ }^{34}$ Ibídem. busca visualizar de forma crítica y mediante el juego cuestiones sobre la vida en el contexto urbano, bajo la premisa de que "el Arte cambiará el mundo cuando sea parte de la vida cotidiana" ${ }^{\prime 35}$. Con sus obras atacan las situaciones que provocan que los ciudadanos se conviertan en meros consumidores de la ciudad ${ }^{36}$. En este sentido realizan acciones como Make a city, un proyecto para Medialab-Prado en el que proponen amueblar la ciudad para hacerla propia, es decir, ante la desaparición de bancos públicos y la mercantilización de las calles y plazas de las ciudades, plantean la fabricación de elementos de mobiliario urbano de forma colaborativa, mediante el uso de impresoras 3D y software libre. Trabajan en otro proyecto que formula una reflexión crítica sobre la utilización del espacio publicitario dentro de las ciudades.

Sus proyectos, desarrollados sobre todo en Madrid - aunque en 2015 realizarán uno en la India-, son una llamada de atención ante la mercantilización de las ciudades, diseñadas por intereses económicos, afectando a la vida de sus habitantes. Ante esta realidad proponen al ciudadano la apropiación del territorio para alejarlo de ganancias privadas. Un ejemplo es el proyecto Hautôvia, la creación ficticia de un Estado Soberado ubicado en la M40, donde se mezcla lo performativo y lo documental.

ARTE PARA LA CIUDADANÍA. CANALES DE DIFUSIÓN Y CONSERVACIÓN DE LAS OBRAS

¿La sociedad siente que el Arte le pertenece? ¿O emite un juicio desde los mensajes que se quieren difundir desde sectores más conservadores que se centran en un papel pasivo del espectador? Nos enfrentamos sin duda ante una comunicación difícil. El contacto fortuito con lo contemporáneo nunca ha sido

${ }^{35}$ TRUTHBEHIND 404 (Correo electrónico, 19 de enero de 2015).

${ }^{36}$ Consultado el 11 de febrero de 2015. URL: http:// www.truthbehind404.com/ 
fácil, pensemos en los primeros Salones Ilustrados y desde ese momento hasta nuestros días en la supremacía de la tríada artística, pintura, escultura y arquitectura y de lo figurativo. Pero si no hablamos como en el s. XVIII, ni nos vestimos como en el s. XIX, tal vez debamos afrontar que el Arte contemporáneo es el de nuestro tiempo, y para ello debemos entender lo contemporáneo tal y como lo define la Real Academia de la Lengua, "perteneciente o relativo al tiempo o época en el que se vive". El artista Jorge Oteiza ${ }^{37}$, Premio Príncipe de Asturias de las Artes, así lo reivindicaba en una pegatina que realizó durante la transición y que decía: "El pueblo que no tiene una poesía actual, una escultura actual y un teatro actual no tiene derecho a mostrar en público una herencia que no es capaz de continuar (y que no puede comprender)" ${ }^{\prime \prime 38}$.

Cada vez son más representativas las relaciones que se establecen entre la ciencia y el Arte intentando desentrañar los mecanismos mentales que se activan con la percepción de la obra y los beneficios que genera en la formación del individuo; así lo expone J.C. Guillén en una reflexión sobre el tema: "El Arte en todas sus manifestaciones constituye una característica esencial que identifica al ser humano, ha permitido transmitir la cultura en toda su extensión y ha sido y es básico para su supervivencia (...) La educación artística es una necesidad no porque nos haga más inteligentes sino porque nos permite adquirir toda una serie de competencias y rutinas mentales que están en plena consonancia con la naturaleza social del ser humano y que son imprescindibles para el aprendizaje de cualquier contenido curricular. Y esto es útil para todos los alumnos, por lo que se convierte en una forma estupenda de atender la diversidad en el aula" ${ }^{\prime \prime}$.

${ }^{37}$ C. MARTÍNEZ GORRIARÁN, Oteiza, hacedor de vacíos, Madrid, 2011.

${ }^{38}$ Consultado el 20 de febrero de 2015. http://www. fsancho-sabio.es/html/Peg_cultura.html

${ }^{39}$ J. C. GUILLÉN, “¿Por qué el cerebro humano necesita el arte?", Escuela con cerebro, 2015, consultado el
Cuando la obra de Arte se crea con pretensiones sociales, alejada de los circuitos convencionales del Arte como ferias, galerías y concursos, los canales de difusión pasan por el uso de internet como vehículo no sólo de difusión, sino de registro y de vínculo entre los propios artistas y con la ciudadanía. Además, muchas de las creaciones tienen un carácter efímero, bien porque de ellas lo que importa es la experiencia y el contacto directo con el espectador, que voluntaria o involuntariamente está presente en el momento y en el lugar justo, o bien porque tienen carácter de ilegal. En estos casos el registro fotográfico y el documental en video son los únicos testigos de la acción y un buen recurso para mostrar no sólo el momento exacto de la intervención artística, sino el proceso previo e incluso posterior; además de la georreferenciación, que permite localizar exactamente algunas de las creaciones como los Crossroad de Boa Mistura. El reportaje fotográfico en forma de dossier o el documental en video ha sido muy usado por artistas como Yolanda Domínguez, Basurama y Boa Mistura, que han difundido sus acciones a través de internet de forma gratuita. Esta plataforma les ha permitido no sólo visibilizar su trabajo entre la comunidad artística, sino que han conseguido que la prensa se haya hecho eco de sus creaciones, de forma que en ocasiones, como ya se mencionó en el caso de la acción Registro de Yolanda Domínguez, la propuesta sobrepase al mismo creador y alcance un verdadero eco colectivo.

Las redes sociales como Facebook, Twitter o plataformas como Youtube o Vimeo, son los canales principales, por encima de las propias webs o blogs de los artistas, pues permiten hacer un seguimiento casi a tiempo real de sus proyectos. Además, tal y como afirma Claudia Frau, la tecnología permite trabajar con objetivos mayores.

18 de febrero de 2015. URL: https://escuelaconcerebro. wordpress.com/2015/01/31/por-que-el-cerebro-humano-necesita-el-arte/. 
En los casos de actividades performativas es evidente que poseen un carácter efímero y el único registro es la imagen, pero cuando queda un elemento material, especialmente en los casos de las intervenciones de Boa Mistura y Basurama, resta un proceso de conservación o degradación de las obras. Este aspecto resulta muy interesante puesto que las obras que fueron creadas para un colectivo, un barrio concreto, son los usufructuarios quienes quedan a cargo de los autoparques o los crossroad. En el caso de Basurama, cuando se crea para rehabilitar un solar o un espacio de la ciudad, es la propia comunidad la que se implica en el mantenimiento, aunque en muchas ocasiones las autoconstrucciones no disponen de los certificados exigidos, por lo que tiene una duración breve, pero no creen que sea un problema puesto que la perdurabilidad no es el objetivo de sus intervenciones sino "el proceso y las capacidades, la adquisición de autonomía y el poder de cambio de diseño y cambio de tu propio entorno" 40 .

Boa Mistura se complace al ver como sus trabajos más cercanos, los de Madrid, las que ven cada día, van mutando; consideran que son obras vivas que van envejeciendo, como todo en la naturaleza: nace, envejece y termina muriendo. Son conscientes de la visión "romántica" que tienen del Arte urbano, lo que no supone una despreocupación por su parte de las creaciones, por lo que tratan de que tengan una vida lo más larga posible, preparando apropiadamente el soporte y usando pinturas adecuadas para el lugar. Incluso cuando son encargo aplican una imprimación que las proteja. Aunque en ocasiones algún Ayuntamiento ha querido restaurar una de sus obras, consideran que una vez terminan su trabajo la obra es de la comunidad, por lo que el hecho de que sean ellos mismos quienes la cuiden y respeten lo creen un logro, puesto que su obra ha cumplido su función: "que ese trabajo conjunto sea una chispa de inspiración, que al trans-

${ }^{40}$ BASURAMA (Correo electrónico, 3 de noviembre de 2014). formar el lugar en el que viven con sus propias manos haga que se sientan más orgullosos de él y lo cuiden y respeten" ${ }^{\prime \prime 1}$. Recientemente han llevado a cabo la restauración del mural "Somos Luz" en Sao Paolo, gracias a la colaboración de Odebrecht y Luz Botero y con la participación de los propios vecinos.

\section{CONCLUSIONES}

El Arte con utilidad social constituye una de las variantes con mayor proyección en las últimas décadas. Su visibilidad mediática lo valida como una posible opción entre las ya existentes, pero en ámbitos más académicos no tiene tanta repercusión porque sus propios medios de estudio son diversos como hemos puesto de manifiesto en este texto en el que ha sido esencial la colaboración directa con los artistas.

El análisis de este tipo de intervenciones artísticas realizadas de forma individual o colectiva demuestra su capacidad para generar cambios; transformar ciudades, relaciones sociales y realidades individuales. El Arte social del siglo XXI utiliza la ciudad no sólo como un telón de fondo o el escenario donde transcurre la acción, sino que la convierte en protagonista de los cambios e incluso en generadora de las transformaciones sociales que se buscan, porque para llegar a todo el conjunto de la ciudadanía nada hay más visible que las propias calles de la ciudad. Este Arte, en ocasiones ilegal, con un carácter efímero e incluso romántico, no es generado por los artistas como un medio para ganarse la vida, de hecho suelen correr con los costes a los que en ocasiones hay que sumar las multas por intervenir en el espacio urbano sin los permisos pertinentes. Uno de los puntos más interesantes de estos artistas es que en la mayoría de los casos buscan un Arte participativo, por lo que se introduce el matiz educacional. Los artistas no generan obras, sino conocimientos que sirven de herramienta para promover un cambio en las

${ }^{41}$ BOA MISTURA (Correo electrónico, 30 de junio de 2014 y 16 de octubre de 2014). 
comunidades. El fomento de estos trabajos pone de manifiesto la importancia del estímulo creativo y el carácter activo en el desarrollo de los individuos.

Otra de las cuestiones interesantes de este tipo de trabajos son las alianzas que se generan entre artistas de intereses comunes, reforzando la tendencia existente en la actualidad a trabajar de forma cooperativa o coworking que es aplicable a todas las área de conocimiento ${ }^{42}$.
Este tipo de arte, como fenómeno reciente, necesitará tiempo para que los futuros manuales de historia del Arte sean los que establezcan las cronologías y la selección de autores que lo representan. No obstante, creemos que la labor del historiador del Arte no debe centrarse sólo en periodos pretéritos sino que debe ir creando una base para las futuras investigaciones. Esa es en parte la intención de nuestro texto. 